LEGAL ESSAYS IN TRIBUTE TO

ORRIN KIP MCMURRAY 


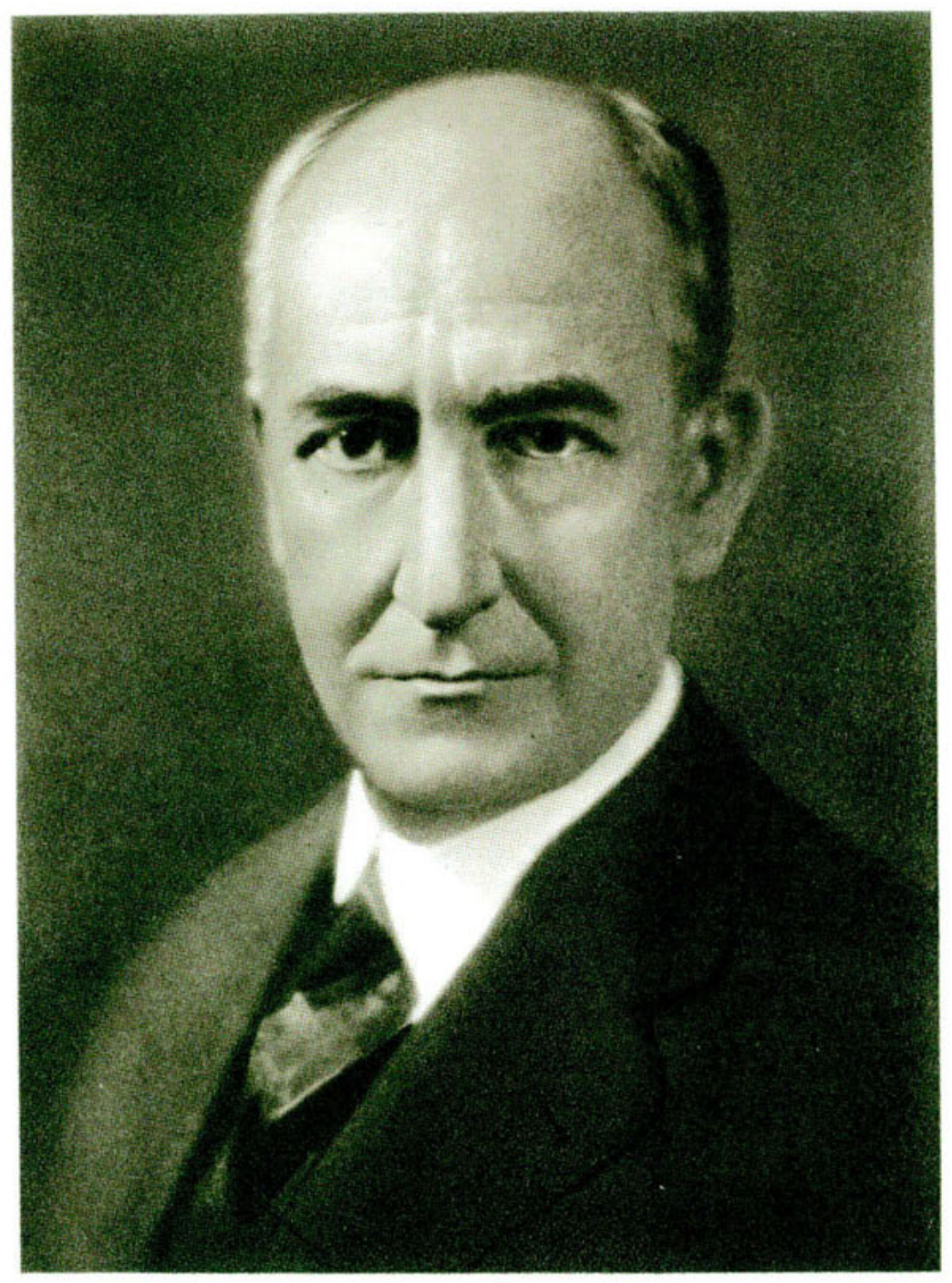

ORRIN KIP MCMURRAY 


\title{
LEGAL ESSAYS
}

In Tribute to

\section{ORRIN KIP MCMURRAY}

\author{
EDITED BY \\ MAX RADIN AND A. M. KIDD
}

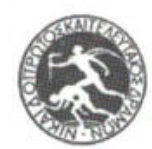

Published for

University of California

Law School Association

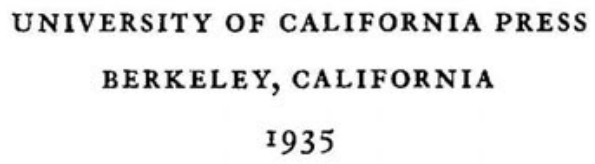




\section{UNIVERSITY OF CALIFORNIA PRESS}

BERKELEY, CALIFORNIA

CAMBRIDGE UNIVERSITY PRESS

LONDON, ENGLAND

COPYRIGHT, I 935

BY THE

REGENTS OF THE UNIVERSITY OF CALIFORNIA

PRINTED IN THE UNITED STATES OF AMERICA BY SAMUEL T. FARQUHAR, UNIVERSITY PRINTER 